\title{
Peran Sosial Guru Pendidikan Agama Islam Di Wilayah Pesisir Utara Pulau Jawa
}

\author{
Arum Yuli Dwi Rahmawati ${ }^{1}$, Muh. Nasruddin ${ }^{2 *}$, Imroatun, ${ }^{3}$ \\ ${ }^{1,2}$ Universitas Cokroaminoto Yogyakarta, ${ }^{3}$ UIN Sultan Maulana Hasanuddin Banten \\ *Penulis Koresponden, email: mohn98294@gmail.com
}

\begin{abstract}
Abstrak
Artikel ini berupaya mengidentifikasi secara kualitatif tentang pendidikan agama Islam non-formal di wilayah pesisir pulau besar Jawa bagian utara, khususnya tentang Peran social guru PAI tingkat SD di desa Demangharjo Kabupeten Tegal termasuk problematika yang mereka dalam pelaksanaanya. Data dikumpulkan dengan cara observasi langsung dan wawancara langsung dengan guru PAI SD yang terlibat dalam kegiatan PAI non formal di masjid desa. Triangulasi dalam metode pengumpulan data yang berasal dari observasi dan wawancara dipilih guna validitas sebelum dianalisis dengan model interaktif, mulai pengumpulan data, reduksi data, sampai pada penarikan kesimpulan. Penelitan ini meyimpulkan bahwa Peran guru PAI tingkat SD dalam pendidikan informal pada wilayah pesisir utara memiliki keunikan tersendiri yang mengombinasikan hasil temuan tentang peran guru di desa pada wilayah pesisir berkepulauan dan perkotaan pedalaman dengan mempertimbangkan kekhasan desa Demangharjo sebagai wilayah penelitian. Problematikanya memang multidimensi, namun disarankan pada keterlibatnan langsung dari orang tua siswa dalam penyelenggaraan pendidikan informal selain kebutuhan insentif dari pemangku kepentingan. Penelitian PAI ini masih bisa dikembangkan karena kondisi social di masingmasing wilayah masih memerlukan pendalaman lebih lanjut meski dalam kondisi geografis yang memiliki kemiripan.
\end{abstract}

Kata Kunci: PAI, non-formal, guru, kompetensi social, wilaya pesisir

\begin{abstract}
This article seeks to qualitatively identify non-formal Islamic religious education in the coastal areas of the large island of northern Java, particularly regarding the social role of Islamic education teachers at the primary education level in the village of Demangharjo, Tegal Regency, including the problems they carry out. Data were collected by direct observation and direct interviews with elementary Islamic education teachers involved in non-formal Islamic education activities in village mosques. Triangulation in data collection methods derived from observations and interviews was chosen for validity before being analyzed with an interactive model, from data collection, data reduction, to drawing conclusions. This research concludes that the role of SD-level Islamic education teachers in informal education in the northern coastal areas is unique in that it combines the findings about the role of teachers in villages in island coastal areas and inland urban areas by
\end{abstract}

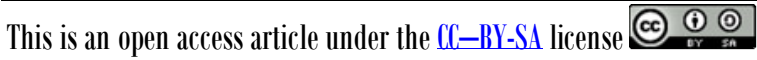


considering the uniqueness of Demangharjo village as a research area. The problem is indeed multidimensional, but it is suggested that the direct involvement of parents of students in the provision of informal education is in addition to the need for incentives from stakeholders. This PAI research can still be developed because the social conditions in each region still require further exploration even though in similar geographical conditions.

Keywords: Islamic religious education, non-formal, teacher, social competence, the coastal areas

\section{Pendahuluan}

Pelaksanaan Pendidikan Agama Islam (PAI) luar sekolah secara ideal dilakukan sebagai usaha bersama masyarakat, tokohnya dan aparat. Bentuknya bisa beragam tergantung kemampuan dan kondisi masyarakat (Musodiqin, Nadjih, dan Nugroho 2017). Bahkan telah diselenggarakan saat aktivitas pasar berjalan (Maulidiah, Aisyah, dan Nasrudin 2017). Diantara pihak terkait yaitu : guru PAI, orang tua dan masyarakat. Gurunya sebagai motor diharapkan mampu membimbing, membina dan mengarahkan peserta didik menjadi anak yang baik, berkepribadian muslim, berakhlak, berdedikasi tinggi dan beriman pada Allah. Dengan kata lain bahwa PAI akan berjalan dengan baik sesuai harapan.

PAI tidak bisa bergantung pada pendidikan formal. Secara mendasar bahkan pendidikan sendiri harus melibatkan semua pihak. Karena itu pendidikan al-Quran bisa saja dilakukan para di masjid atau lembaga pendidikan non-formal lainnya secara permanen atau insidental (Arifudin et al. 2019; Rahayu et al. 2019). Maka PAI telah menjadi usaha orang dewasa secara sadar untuk membimbing dan mengembangkan kepribadian serta kemampuan dasar peserta didik baik dalam bentuk pendidikan formal maupun non formal (Faisal 2006). Untuk PAI, Dirjen Bimbaga Islam menjelaskannya sebagai pendidikan dengan melalui ajaran-ajaran agama Islam, yaitu usaha berupa bimbingan dan asuhan terhadap peserta didik agar nantinya setelah selesai dari pendidikan ia dapat memahami, menghayati, dan mengamalkan ajaran-ajaran agama Islam yang telah diyakininnya secara keseluruhannya, serta menjadikan agama Islam itu sebagai suatu pandang hidupnya dari keselamatan dan kesejahteraan hidup di dunia dan akherat kelak. Marimba (1989) kemudian menyesuaikannya dengan menyebutnya bimbingan jasmani dan rohani berdasarkan hukum-hukum Islam menuju kepada terbentuknya kepribadian utama menurut ukuran-ukuran Islam. Sedangkan kepribadian yang utama itu tercermin dalam budi pekerti atau akhlak yang mulia, ilmu pengetahuan yang luas mendalam, dan kecakapan 
serta ketrampilan dalam berkarya yang bermanfaat bagi masyarakatnya, sesuai dangan ajaran Islam (Zuhairini 2015). Pola demikian bahkan lebih tepat dijalankan dalam pendidikan pesantren yang berkomitmen kuat kepada pendidikan masyarakat (Nadjib H. et al. 2019).

Tuntutan definitif dalam PAI yang demikian tidak bisa dipegang sepenuhnya oleh guru PAI dalam pendidikan formal. Ia harus terlibat dalam berbagai ruang dan lingkungan agar tujuan-tujuan PAI bisa tercipta dalam masyarakat. Secara professional, guru menurut Undang-Undang Republik Indonesia Nomor 14 Tahun 2005 tentang Guru dan Dosen, bahwa guru adalah pendidik profesional dengan tugas utama mendidik, mengajar, membimbing, mengarahkan, melatih, menilai, dan mengevaluasi peserta didik pada pendidikan usia dini, pendidikan dasar, dan pendidikan menengah jalur pendidikan formal (Minarti 2013).

Namun guru tidak sebatas berkutat pada profesi saja. Minati merujuk asal kata guru dari bahasa Sansekerta yang artinya berat, besar, penting, baik sekali, terhormat, dan pengajar. Pada bahasa Inggris, teacher yang berarti guru atau pengajar, edukator yang berarti pendidik atau ahli mendidik, dan tutor yang berarti guru pribadi, guru yang mengajar di rumah, atau guru yang memberi les (Mujtahid 2011). Djamarah telah menekankan pada pandangan masyarakat bahwa guru dalam pandangan adalah orang yang melaksanakan pendidikan di tempat-tempat tertentu, tidak harus dilembaga formal (Djamarah 2000). Nata menggeneralisasinya seseorang yang memberikan pengetahuan, keterampilan atau pengalaman kepada orang lain (Nata 2005). Sementara Ramayulis berfokus tujuan dari keberadaan guru. orang yang bertanggung jawab untuk membimbingpeserta didik menjadi manusia yang manusiawi yang memanusiakan manusia, sehingga tugas utamanya, mendidik, mengajar,membimbing, mengarahkan, melatih, menilai dan mengevaluasi murid dalam pendidikan (Ramayulis 2013).

Dengan keterlibatan penuh guru dalam dalam setiap lingkungan pendidikan, maka arah kemajuan masyakat bisa ditebak. Seperti yang diutarakan oleh Ashoumi (2014), masyarakat yang kurang memperhatikan pendidikan, maka keterbelakangan selalu membayangi dari sisi intelektual maupun sosial kultural. pendidikan masyarakat yang bersifat pasif dan konservatif akan menghasilkan masyarakat dalam produktifitas dan kreatifitas yang tidak memadai. Pendidikan telah menjadi sarana efektif mengupayakan transformasi sosial dengan berpijak pada budaya masyarakat kepada generasi selanjutnya. Dalam penelitian Indy dkk. di desa Tumaluntung menegaskan 
apa yang Ashoumi simpulkan (Indy, Waani, dan Kandowangko 2019). Mereka telah sadar pendidikan merupakan usaha pengembangan potensi diri secara formal, informal dan non formal. Ketiga pendidikan itu saling melengkapi dan menunjang satu dengan lainnya.

Sebagai guru professional bahkan dituntut memiliki kompetensi sosial yang berkaitan dengann perannya secara social, dalam dan luar sekolah. Dalam Standar Nasional Pendidikan Kompetensi sosial menjadi kompetensi keempat yang dimaksudkan dalam landasan yuridis pendidikan Indonesia. Kompetensi ini berkaitan dengan kemampuan guru berinteraksi dengan peserta didik dan orang yang ada disekitar dirinya. Model komunikasi personal cendrung lebih mudah diterima oleh peserta didik dan masyarakat. Dalam konteks ini hendaknya guru memiliki strategi dan pendekatan dalam melakukan komunikasi yang cendrung bersifat horizontal (Republik Indonesia 2005).

Kompetensi Sosial terkait dengan kemampuan guru sebagai makhluk sosial dalam berinteraksi dengan orang lain. Sagala menjelaskan kompetensi itu antara lain; a)Memahami dan menghargai perbedaan (respek) serta memiliki kemampuan mengelola konflik. b) Melaksanakan kerja sama secara harmonis dengan kawan sejawat, kepala sekolah, dan pihak-pihak terkait lainnya. c)Membangun kerja tim (teamwork) yang kompak, cerdas, dinamis, dan lincah. d)Melaksanakan komunikasi (oral, tertulis, tergambar) secara efektif dan menyenangkan dengan seluruh warga sekolah, orang tua peserta didik, dengan kesadaran sepenuhnya bahwa masing-masing memiliki peran dan tanggung jawab terhadap kemajuan pembelajaran. e) Memiliki kemampuan memahami dan menginternalisasikan perubahan lingkungan yang berpengaruh dengan tugasnya (Sagala 2009).

Mulyasa menjabarkan lebih lanjut aspek social dari profesi guru. Sebagai petugas masyarakat, ia bertugas bertugas membina masyarakat agar masyarakat berpartisipasi dalam membangunan. Untuk melaksanakan tugas itu, Mulyasa mengungkap guru harus memiliki kompetensi sebagai berikut. Dengan demikian ia perlu; 1) Mampu berkomunikasi dengan masyarakat, 2) Mampu bergaul dan melayani masyarakat dengan baik, 3) Mampu mendorong dan menunjang kreatifitas masyarakat, 4) Menjaga emosi dan prilaku yang kurang baik (Mulyasa 2013).

Secara filosofis, Idrus pun menyimpulkan kompetensi social menjadi modal social guru dalam berkiprah dalam masyarakat (Idrus 2005). Sya'bani dalam penelitiannya tentang peran peran sosial guru pendidikan agama islam 
SMAN 3 Mataram dalam pembinaan kerukunan umat beragama di masyarakat perkotaan juga menemjukan hal yang sama.(Sya'bani 2016) Hilal menjabarkan penelitian tentang harapan masyarakat pada peran social guru PAI SMP di Kecamatan Tempel yang ada di perkotaan lebih dalam dibanding Mataram. Mereka telah menjadikan pribadi dan keluarga sebagai contoh perilaku yang baik. Bimbingan dan dakwah guru PAI juga dibutuhkan tanpa ada perlakuan pembedaaan status social (Hilal 2019).

Peran guru di masyarakat terpencil di wilayah pesisir dan kepulauan telah ditelusuri oleh Waqif. Ia menjelaskan akar permasalahan masyarakat terhadap kebutuhan pendidikan bagi pengentasan kemiskinan menjadi tanggung jawab guru di wilayah tersebut. yakni selain pelaksanaan profesi di sekolah, guru juga berperan multidimensi menjadi pendamping masyarakat bagi pengentasan kemiskinan.(Waqif 2017)

Dengan keahliannya, meski bukan hal yang tidak mungkin, guru PAI tentu tidak bisa selalu focus kemiskinan masyarakat meski sama-sama di tinggal wilayah pesisir. Di desa Demangharjo Kecamatan Warurejo Kabupaten Tegal menjadi Salah satu desa pesisir di Kabupaten Tegal. Menurut statistik diatas, maka desa Demangharjo kecamatan Warureja kabupaten Tegal wilayahnya cukup padat, karena memiliki kepadatan tinggi sejumlah 15064 karena Warureja merupakan wilayah Pesisir/nelayan cukup luas, luas $61.39 \mathrm{~m} 2$. Rupa-rupanya jumlah wanita yang ada sekitar 4546 jiwa yagn tidak berselisih jauh. Adapun jumlah Kepala Keluarga terdiri dari 2289 jiwa.(Anon n.d.)

Wilayah Demangharjo memang di pesisir tetapi tidak dalam wilayah kepulauan bahkan menjadi jalur penting di pulau besar Jawa menuju pusat pemerintahan Negara. Para guru PAI tingkat sekolah dasar (SD) di situ telah berusaha dalam memantapkan dan mengembangkan PAI di luar sekolah bagi anak. Upaya tersebut antara lain : telah dilakukan pembinaan keagamaan terhadap anak dalam bentuk pengajian al-Quran usai salat magrib dan isya, dan telah dilakukan pembinaan keagamaan pada orang tua agar bisa mendorong anak-anaknya untuk mengikuti kegiatan PAI di masjid dan musalla desa.

Proses-proses di atas tidak lepas dari peran serta Guru PAI sebagai pendorong dan penunjang keagamaan Islam di masyarakat. Dengan kata lain kehadiran guru PAI sangat menentukan terhadap perubahan dan perkembangan PAI terutama bagi anak-anak.

Artikel ini berupaya mengidentifikasi lebih lanjut peran guru PAI tingkat SD di desa Demangharjo yang termasuk wilayah pesisir pulau besar 
Jawa bagian utara. Hal itu dimaksudkan untuk menganalisis problematika yang mereka hadapi saat menjalankan peran sosialnya di masyarakat sekitar tempat tinggalnya. Dengan demikian bisa menjadi bahan penting memajukan PAI di wilayah pesisir Indonesia secara umum.

\section{Metode}

Penelitian kualitatif ini menggunakan metode pengumpulan data, yaitu; observasi langsung tentang peran guru PAI SD dalam masyarakat desa Demangharjo. Lokasi pengamatan adalah dua masjid penting di desa, yaitu: Baitul muslimin dan Baiturrahman. Metode selanjutnya adalah guru SD yang terlibat dalam kegiatan di masjid tersebut. Setelah ditelusuri ada 5 guru yang terlibat yang sekaligus menjadi tokoh masyarakat di desa tersebut. Merekalah informan dalam penelitian ini. Triangulasi dilakukan untuk meningkatkan validitas dalam penelitian kualitatif. Instrumen itu berupa teknis pemeriksaan keabsahan data yang memanfaatkan sesuatu yang lain (Moleong 2007). Yang dipilih kemudian adalah triangulasi dalam metode pengumpulan data yang berasal dari observasi dan wawancara. Hasil pengumpulan data diolah dengan model interaktif baik dalam pengumpulan data, reduksi data, sampai pada penarikan kesimpulan.

\section{Peran Guru PAI dalam Masyarakat}

Kegiatan PAI di desa tersebut dilakukan di dua tempat, bentuk sekolah seperti: madrasah ibtidaiyah, madrasah diniyah, dan sekolah dasar. Yang lain, PAI di luar sekolah, yang kegiatannya berbentuk pengajian Qur'an terhadap anak-anak di Musholla Baitul Muslimin dan Masjid Baiturrahman, pengajian orang tua, masjlis ta'lim dan pengajian remaja.

Sistem sekolah dilakukan pada waktu sore yang bertempat di madrasah diniyah. Dan bagi mereka masuknya sore, maka wajib di waktu paginya masuk SD. Adapun anak yang mengikuti kegiatan pendidikan agama islam di MI, maka waktunya adalah sore hari. Untuk lebih jelasnya tentang keadaan PAI sistem sekolah yang ada di Demangharjo, dan jumlah pesertanya dapat dilihat pada tabel berikut ini :

Tabel 1

PAI di sekolah desa Demangharjo

\begin{tabular}{|l|l|l|l|l|l|}
\hline \multirow{2}{*}{ No } & \multirow{2}{*}{ Jenis pendidikan } & \multirow{2}{*}{ Banyak } & \multicolumn{4}{|c|}{ Jumlah murid } \\
\cline { 4 - 7 } & & & L & P & Jml. \\
\hline 1. & MI & 2 buah & 10 & 5 & 15 \\
\hline 2. & Madrasah diniyah & 2 buah & 5 & 5 & 10 \\
\hline
\end{tabular}




\begin{tabular}{|l|l|l|l|l|l|}
\hline & Jumlah & 4 buah & 15 & 10 & 25 \\
\hline
\end{tabular}

Tabel tersebut diatas menunjukkan, bahwa jumlah anak yang mengikuti kegiatan PAI sistem sekolah sedikit sekali, bila dibandingkan dengan jumlah penduduk. Adapun pelaksanaan kegiatan PAI luar sekolah di desa Demangharjo dilaksanakan pada malam hari dan bertempat di Musalla Baitul Muslimin dan Masjid Baiturrahman. Untuk lebih jelasnya dapat dilihat pada tabel berikut ini :

Tabel 2

PAI di Luar Sekolah pada desa Demangharjo

\begin{tabular}{|l|l|l|l|l|l|}
\hline \multirow{2}{*}{ No } & \multirow{2}{*}{ Jenis pendidikan } & Banyak & \multicolumn{3}{|l|}{ Jenis murid } \\
\cline { 4 - 7 } & & $\mathrm{L}$ & $\mathrm{P}$ & $\mathrm{Jml}$ \\
\hline 1. & Madrasah Ibtidaiyyah & 2 & 5 & 5 & 10 \\
\hline 2. & Madrasah diniyah & 2 & 5 & 5 & 10 \\
\hline 3. & Rumah & 3 & 5 & 5 & 10 \\
\hline & Jumlah & 7 buah & 15 & 15 & 30 \\
\hline
\end{tabular}

Peranan guru PAI SD di luar sekolah pada desa Demangharjo ada beberapa. Mereka mengajar siswa yang tidak pernah belajar agama di madrasah. Siswa banyak yang tidak mengikuti jalur sekolah karena orang tua tidak mampu membayar sekolah. Siswa yang tidak ikut sekolah 60 persen dan yang ikut sekolah 40 persen. Para guru bertugas memberikan pengajaran di luar sekolah ia menyampaikan pelajaran agar murid memahami dengan baik semua pengtahuan yang telah disampaikan. Selain itu agar terjadi perubahan sikap, keterampilan, kebiasaan hubungan sosial, apresiasi dan sebagainya melalui pengajaran yang diberikan. Untuk mencapai tujuan tersebut maka guru perlu memahami pengetahuan. Bantuan juga diberikan oleh mereka kepada murid agar mereka menemukan dan memecahkan masalahnya sendiri, mengenal diri sendiri, dan menyesuaikan diri dengan lingkungan. Para guru SD itu juga dapat membantu siswanya memecahkan masalahmasalahnya yang dihadapi agar bisa bertanggung tawab secara mandiri saat bersama dengan orang lain (Prastomo et al. 2019).

Seiring dengan perkembangan masyarakat, maka semakin tinggi tuntutan pendidikan Agama Islam bagi anak. Oleh karena itu kehadiran guru agama Islam dalam usaha memantapkan penyelenggaraan di luar sekolah semakin penting. Sejumlah fakta di lapangan menunjukkan bahwa anak belum tentu mendapatkan PAI yang baik dari kedua orang tuanya, 
bahkan karena kesibukan orang tua banyak yang menitipkan anaknya kepada guru PAI baik di masjid Baiturrahman maupun Musalla Baitul Muslimin secara rutin dilakukan setiap malam seusai salat Magrib dan Isya. Untuk itu, keberadaan guru PAI sangat dibutuhkan dalam usaha memajukan, mengembangkan dan memakmurkan pendidikan agama islam untuk anakanak. Ia punya fungsi dan peranan yang cukup besar dalam memajukan masyarakat, khususnya di bidang PAI (Ahmadi 1986).

Di desa Demangharjo Kecamatan Warurejo Kabupaten Tegal, telah ada usaha dalam memantapkan dan mengembangkan PAI di luar sekolah bagi anak yang dilakukan oleh guru PAI. Upaya tersebut antara lain : telah dilakukan pembinaan keagamaan terhadap anak dalam bentuk pengajian alQuran seusai salat magrib dan isya, dan telah dilakukan pembinaan keagamaan pada orang tua agar bisa mendorong anak-anaknya untuk mengikuti kegiatan PAI di masjid Baiturrahman maupun Musalla Baitul Muslimin.

Meski tidak sepenuhnya benar seperti refleksi Wafiq terhadap pengalaman profesi guru yang harus berkutat di kemiskinan masyarakat langsung (Waqif 2017), namun partisipasi aktif dalam telah menjadi titik penting guru PAI dalam Masysarakat. Mereka telah menjadi pemicu kesadaran masyarakat bahwa pendidikan berperan terhadap kemajuan diri dan masyarakat.(Ashoumi 2014; Indy et al. 2019). Peran guru PAI sebenarnya sesuai dengan harapan masyarakat yang ditemukan Hilal, mereka telah menjadi panutan pribadi termasuk keluargaya.(Hilal 2019)

Penguatan kompetensi social guru, (Idrus 2005) juga menjadi factor penting dalam keterlibatan guru PAI dalam masyarakat Demangharjo. Dalam menjalankan fungsinya sebagai pengajar informal tercakup pula tugas sebagai penyampai atau penyaji pelajaran, pemilih dan penyaring bahan pelajaran dan sekaligus sebagai yang memahami landasan dan tujuan pendidikan. Dengan demikian merupakan sarana aktif antara murid dan falsafah negara serta kehidupan masyarakat dengan segala macam ragamnya.

Pandangan pada guru PAI SD di sektor pendidikan informal adalah terfokus pada masa depan anak. tunas-tunas bangsa itu memiliki potensi yang harus dibangun untuk dapat menghadapi tantangan zaman sehingga ia mampu membangun dirinya sendiri dan dapat meningkatkan kesejahteraan dan martabat kemanusiaan. Dengan demikian anak memerlukan PAI tidak sebatas transformasi pengetahuan tapi meluas hingga pengamalan dan pengalaman.

\section{Problematika PAI Non-formal}


Dalam perjalanan PAI non formal tidak bisa terlepas dari berbagai macam permasalahan bagi kemajuannya. Situasi social yang multidimensional dalam masyarakat pesisir seperti Demangharjo memiliki keunikan tersendiri. ketergantuan pada iklim dan situasi kelautan berdampak pada pola pembelajaran PAI nonformal.

Jumlah Tenaga Pendidik kurang memadai. Pertumbuhan dan perkembangan PAI luar sekolah di desa demangharjo tidak begitu pesat. Hal ini dikarenakan masih banyak kekurangan tenaga pengajar agama yang siap pakai. Disamping itu masyarakat masih belum menyadari arti pendidikan agama islam karena mereka lebih dipengaruhi oleh kebudayaankebudayaan yang datang dari luar. Kekurangan tenaga pendidik yang profesional ini diakibatkan kelemahan dalam keterlibatan orang tua dalam pendidikan informal, sehingga banyak orang tua yang berpandangan sempit dalam mendidik anak terutama terhadap pendidikan agama islam luar sekolah. Karena sarana pengembangan dan pembinaan pendidikan agama islam di desa demangharjo itu sebenarnya cukup potensial, namun karena keterbatasan pendidikan maka menjadi faktor penghambat.

Persaingan antar guru mengaji. Adanya persaingan antara guru mengaji dalam mendapatkan murid dapat menjadi penghambat bagi pembinaan pendidikan agama islam, karena bila persaingan telah ada maka akan berdampak negatif bagi pembinaan itu, dengan demikian yang didapat bukan pembinaan, tapi permusuhan.

Penguasaan Metode mengajar. Metode yang dipergunakan oleh guru pendidikan agama islam di dalam mengajar masih klasik tradisional dan monoton. Para guru pendidikan agama islam, guru mengaji dan kyai di desa demangharjo masih dalam tahap membaca didalam menyampaikan ilmu itu, belum mengarah kepada pemahaman dari bacaan itu, untuk dipraktekan dalam kehidupan sehari-hari.

Faktor keragaman budaya. Masyarakat desa demangharjo dengan adanya pengaruh luar dalam arti kebudayaan-kebudayaan yang datang dari luar, termasuk adanya alat-alat modern yang canggih banyak menimbulkan gangguan-gangguan pada anak. Hal ini dengan adanya TV, VCD dan hiburan lainnya, maka anak yang biasanya rajin datang ke masjid waktu sore dan ke Musalla untuk mengikuti kegiatan keagamaan atau mengaji, anak tersebut sering tidak datang, anak lebih cenderung menonton $\mathrm{Tv}$ dan sebagainya dirumah apalagi kalau acaranya menarik terutama waktu magrib. Sehingga dengan adanya penampilan yang ada di Tv, cukup berpengaruh terhadap pertumbuhan dan perkembangan anak. Disamping itu 
masyarakat desa demangharjo sendiri kalau punya hajatan diadakan hiburanhiburan atau pertunjukan-pertunjukan seperti : organ tunggal, wayang golek dan lain-lain. Hal ini jelas menganggu kegiatan anak yang sedang mengikuti PAI luar sekolah, seperti pengajian Qur'an bagi anak dan majlis ta'lim bagi para remaja dan orang tua, karena terpaksa banyak yang meninggalkannya.

Faktor lingkungan keluarga, diantaranya; Orang tua kurang didalam memberikan bimbingan dan pengarahan kepada anak-anaknya. Keluarga yang tidak harmonis dan banyak kesibukan dari para orang tua. Rendahnya tingkat ekonomi dan agama para orang tua. Orang tua kurang mendorong pada anak-anaknya untuk mengikuti kegiatan pendidikan agama islam luar sekolah

Keluarga muda karena Perkawinan dini. Faktor lain yang menjadi penghambat pembinaan pendidikan agama islam pada anak adalah karena perkawinan usia muda. Karena pada masa muda anak sedang rajin dalam mengikuti kegiatan pendidikan agama islam diluar sekolah, seperti pengajian al qur'an, akan tetapi setelah dewasa anak disuruh untuk kawin terutama bagi anak perempuan. Dengan demikian, maka dapat dikatakan bahwa perkawinan usia muda yang dilakukan oleh penduduk setempat menjadi penghambat bagi pembinaan pendidikan agama islam.

Sebagian kecil masyarakat desa Demangharjo memberikan pendidikan dan pembinaan agama islam di rumah masing-masing. Hasil penelitian dilapangan menunjukkan kebanyakan masyarakatnya telah mendidik dan membina anak-anaknya untuk bekerja, sedangkan PAI kurang mendapat perhatian. Hal itu dikecualikan bagi keluarga banyak dilakukan oleh orang tua yang mengerti akan pendidikan dan mereka mempunyai kemampuan untuk itu yang pernah lulus SLTP, SLTA atau lulusan pesantren.

Sekolah merupakan tempat pendidikan yang kedua setelah pendidikan keluarga, karena hubungannya cukup berperan dan sangat penting dalam membina dan membimbing anak kearah kedewasaan dan bertanggung jawab, tetapi tidak menutup kemungkinan justru kadangkadang sekolah dapat merupakan penyebab rendahnya pelaksanaan pendidikan agama islam luar sekolah rendah. hal Ini mungkin bersumber pada guru yang kurang mampu mengatur terhadap peserta didiknya atau kurangnya tenaga guru PAI, fasilitas kurang mendukung, pengurangan jam pelajaran PAI, kurang adanya kerjasama guru dengan orang tua dan masyarakat, kurang adanya hubungan timbal balik antara sekolah dengan orang tua dan masyarakat. 


\section{Kesimpulan}

Peran guru PAI tingkat SD pada wilayah pesisir utara memiliki keunikan tersendiri yang mengombinasikan hasil temuan tentang peran guru di desa pada wilayah pesisir berkepulauan dan perkotaan pedalaman dengan mempertimbngkan kekhasan desa Demangharjo sebagai wilayah penelitian. Peran mereka di PAI informal telah memberikan posisi penting di mata masyarakat selain memperkuat kompetensi social sehingga mendukung profesi utama mereka. Problematinya memang multidimensi. Keterbatasan sumber daya manusia, persaingan yang tidak sehat antar guru, selain pengengaruh lingkungan keluarga dan masyarakat serta pengaruh budaya luar melalui teknologi informasi.

Saran penting untuk memecahkan persoalan PAI di wilayah pesisir utara Jawa adalah mendorong partisipasi aktif keluarga siswa dalam pendidikan. Kebutuhan insentif yang pasti dari para pemangku kepentingan dalam berbagai bentuknya juga perlu dipenuhi untuk mendorong semua pihak sadar PAI bagi kehidupan. Penelitian PAI masih belum usai di sini karena karena kondisi social di masing-masing wilayah masih memerlukan pendalaman lebih lanjut meski dalam kondisi geografis memiliki kemiripan.

\section{Daftar Pustaka}

Ahmadi, Abu. 1986. Metodik Khusus Pendidikan Agama. Bandung: Armico.

Anon. n.d. "Profil Desa Demangharjo, Warureja, Kab. Tegal, Jawa Tengah, Indonesia." Diambil (https://demangharjo.tegal.website/).

Arifudin, Wahyu Amin, Nurul Fatihah, Ahmad Echsan, Lailatul Maftuhah, Difla Nadjih, dan Agus Pandoman. 2019. "Kesadaran Beragama Pelaku Pariwisata di Kawasan Malioboro." Nuansa Akademik: Jurnal Pembangunan Masyarakat 4(2):117-32.

Ashoumi, Hilyah. 2014. "Masyarakat Dan Pendidikan Sebagai Sistem Sosial." At - Tahdzib 2(1):16.

Djamarah, Syaiful Bahari. 2000. Guru dan Anak Didik dalam Interaksi Edukatif. Jakarta: PT.Rineka Cipta.

Faisal, Sanafiah. 2006. Pendidikan Formal Maupun Non Formal. Surabaya: Usaha Nasional.

Hilal, Umi Zakiyatul. 2019. "Peran Sosial Guru Pai Dalam Masyarakat Studi Pada Guru Pai Smp Di Kecamatan Tempel." Jurnal Al Qalam 20(1):6577.

Idrus, Muhammad. 2005. "Kompetensi Sosial Sebagai Modal Sosial Guru." El-Tarbawi 13(8):37-56.

Indy, Ryan, Fonny J. Waani, dan N. Kandowangko. 2019. "Peran Pendidikan Dalam Proses Perubahan Sosial Di Desa Tumaluntung Kecamatan Kauditan Kabupaten Minahasa Utara." HOLISTIK, Journal Of Social and Culture 12(4):1-21.

Marimba, Ahmad D. 1989. Pengantar Filsafat Pendidikan. Bandung: A1 
Ma'arif.

Maulidiah, Khilda, Siti Aisyah, dan Moh Nasrudin. 2017. "Sekolah Pasar Rakyat Sambilegi Alternatif Pendidikan Agama Islam Dalam Masyarakat." Ulumuddin: Jurnal Ilmu-ilmu Keislaman 7(1):31-44.

Minarti, Sri. 2013. Ilmu Pendidikan Islam: Fakta Teoritis-Filosofis dan AplikatifNormatif. Jakarta: Amzah.

Moleong, J. 2007. Metode Penelitian Kualitatif. Bandung: Remaja Rosda Karya. Mujtahid. 2011. Pengembangan Profesi Guru. Malang: UIN Maliki Press.

Mulyasa, H. E. 2013. Uji Kompetensi dan Penilaian Kinerja Guru. Bandung: Remaja Rosda Karya.

Musodiqin, Muhammad, Difla Nadjih, dan Taufik Nugroho. 2017. "Implementasi Sorogan Dalam Pembelajaran Al-Qur'an Pada Madrasah Diniyah Takmiliyah." Ulumuddin: Jurnal Ilmu-ilmu Keislaman 7(1):59-71.

Nadjib H., Ahmad, Muh. Jamaluddin, Hilman Haroen, Taufik Nugroho, dan Paiman Paiman. 2019. "Penanaman Nilai-Nilai Kemasyarakatan Di Pesantren Modern." Nuansa Akademik Jurnal Pembangunan Masyarakat 4(1):17-32.

Nata, Abuddin. 2005. Filsafat Pendidikan Islam. Jakarta: Gaya Media Pratama.

Prastomo, Wiranthi, Muhiyatul Huliyah, M. Nasrudin, Intan Kusumawati, dan AN Ari Bowo. 2019. "Hizbul Wathan Bagi Pendidikan Kemandirian Tingkat Sekolah Dasar." Nuansa Akademik Jurnal Pembangunan Masyarakat 4(1):47-62.

Rahayu, Supriati H., Hidayatul Huda, Joko Wahono, Difla Nadjih, dan A. Zain Sarnoto. 2019. "Implementasi Pendidikan Quran Tingkat Lanjut Bagi Santri Usia Dewasa." Nuansa Akademik Jurnal Pembangunan Masyarakat 4(1):63-78.

Ramayulis. 2013. Profesi dan Etika Keguruan. Jakarta: Kalam Mulia.

Republik Indonesia. 2005. Undang-Undang RI Nomor 14 Tahun 2005 tentang Guru dan Dosen.

Sagala, Syaiful. 2009. Kemampuan Profesional Guru dan Tenaga Kependidikan. Bandung: Alfabeta.

Sya'bani, Sri Andria. 2016. "Peran Sosial Guru Pendidikan Agama Islam Dalam Pembinaan Kerukunan Umat Beragama Di SMAN 3 Mataram." Al-Munawwarah: Jurnal Pendidikan Islam 8(1):55-65.

Waqif, Abdul. 2017. "Peran Guru Di Wilayah Pesisir Dan Terpencil." Eklektika: Jurnal Pemikiran dan Penelitian Administrasi Pendidikan 5(1'):1827.

Zuhairini. 2015. Filsafat Pendidikan Islam. Jakarta: Bumi Aksara. 